krankt ist an einer Art Lungenentzündung, aber niclit gefälırlicl, wie mir meine Schwägerin von Hessen meldet. Sie ist walırhaftig zu allen möglichen Krankheiten verurteilt."

Am 21. Juli meldet der König von Charlottenburg aus seinenı Bruder naclı Homburg den Tod der Gemahlin:

,Lieber Bruder, iclı habe das grenzenlose unaussprechliche Unglück gehabt, mein ganzes Gläck zu verlieren. Meine Frau ist mir durcl den Tod entrissen. Sie starb in Hohenzieritz den 19. nach einem dreiwöchentlichen Krankenlager, das mir in den drei letzten Tagen Besorgnis erregte, am Brustkrampf nach gehabter Lingenentzündung. Ich bin gänzlich trostlos. Mehr zu schreiben vermag ich nicht. Bedauere mich, lieber Bruder, sowie mir deine Frau auch tun wird, wenn jch mich empfehle. Lebe wohl!

Friedricl Wilhelm.

Naclischrift: Diese Nacht bin ich von Hohenzieritz gekommen."

Von unbekannter, offenbar sachkundiger Hand in deutscher Sprache (die Briefe der Prinzessin sind größtentejls französisch) findet sich bei den Briefen folgender Bericht über die Todesursache.

,Da noch eines, Sie befehlen zu wissen, was man für Ursache angiebt. zum Tode der Königin. Die Krankheit soll zwar leicht gewesen seyn. Doch glaubt man, daß die Lunge zu schwach war, daß sie wahrscheinlicl in der Folge die Lungensucht bekoinmen hatte. Die Ursache des Todes ist ein kleiner Polyp am Herzen gewesen, in der Krankheit erzeugt durcl Wallungen des Bluts, veranla.ßt von den häufigen Ohnmachten - dieser hinderte die gehörige Funktion des Herzens und erstickte sie endlich dieser Polyp hätte niclıt entstehen können, wenn sie sich nicht früher zu sehr das Blut verdickt hätte durch die wenige Bewegung, die sie sich gab. Ihr Herz wal überhaupt unproportioniert klein, sodaß sie wirklich bei vollem Sinne des Wortes durchs Herz gestorben ist, sie, die nur darin lebte."

In melireren späteren Briefen schreibt Marianne über die tiefe Trauer des Königs, der u. a. zu ilır äußerte:

,Wenn so viele schwere Findrücke auf einem einstürnen, und zuletzt noch dieser Schlag einem trifft, so muß ja die Natur endlich interliegen, und ich denke, es wird bald mit mir aus sein."

\title{
Feuilleton.
}

\section{Briefliche Notizen über den Tod der Königin Luise.}

\section{Zum 19. Juli 1910.}

Von Dr. Curt Schelenz, z. Z. in Cassel.

Am 19. Juli jährt sich zum hundertsten Male der Tag, an dem Preußens unvergeßliche Königin Luise 1810 aus ihrem in den letzten Jahren so kuminervollen Leben abgerufen wurde. Ueber ihre Erkrankung und die Ursache ihres Todes finden sich in bisher ziemlich unbekannten Briefen ihrer Schwägerin, der Prinzessin Marianne von Preußen (geb. Prinzessin von Hessen-Homburg), der Gemahlin des Prinzen Wilhelm von Preußen, des Bruders des Königs Friedrich Wilhelm III. einige interessante Notizen ${ }^{1}$.

Am 11. Juli erhielt Prinzessin Marianne bei ilırem Kuraufenthalt in Ems die ersten Nachrichten über die Erklankung der Königin. Sie schreibt darüber an ihre Mutter nach Homburg:

,Denken Sie, liebe Mutter, daß die arme Königin in Strelitz er-

1) Vgl. Dr. Berger-Gießen, Briefe der Prinzessin Marianne von Preußen, Hessenland 1909, No. 23. 